\title{
Dual-chamber ICD implantation via a persistent left superior vena cava - use of an innominate vein for the placement of a right ventricular cardioverter-defibrillator lead implantation
}

\author{
Implantacja dwujamowego kardiowertera-defibrylatora serca przez przetrwałą \\ żyłę główną górną — wykorzystanie żyły bezimiennej do implantacji elektrody \\ prawokomorowej kardiowerterowo-defibrylującej
}

\author{
Andrzej Ząbek ${ }^{1}$, Krzysztof Boczar ${ }^{1}$, Maciej Dębski ${ }^{1}$, Jacek Lelakowski ${ }^{1,2}$, Barbara Małecka ${ }^{1,2}$ \\ 'Department of Electrocardiology, The John Paul II Hospital in Krakow, Krakow, Poland \\ 2Institute of Cardiology, Jaciellonian University Medical College, Krakow, Poland
}

A 46-year-old male was referred for dual-chamber implantable cardioverter-defibrillator (ICD) implantation due to ischaemic cardiomyopathy. His medical history was notable for an intermittent third-degree atrioventricular block. During the procedure a persistent left superior vena cava (PLSVC) was detected. After several attempts we succeeded in placing the shock lead (St. Jude Durata) via cephalic vein venesection, then through the innominate vein (IV) and right superior vena cava into the right ventricle. The atrial lead, a Medtronic 5076, could not be inserted via the same route (Fig. 1A). Venography revealed lack of contrast filling in IV (Fig. 1B). Despite the lack of lumen inside the IV the hydrophilic guidewire was advanced into the right atrium (Fig. 1C); however, subsequent venography revealed a small dissection of the vein (Fig. 1D, E). Finally, the atrial lead was implanted through the PLSVC (Fig. 1F). The procedure remained uneventful thereafter. In both chambers the optimal electrical parameters were obtained. Chest X-ray confirmed the position of the leads (Fig. 2). Angio-computed tomography performed in order to exclude bleeding from IV showed a complete lack of contrast flow through IV, which was totally filled by the defibrillator lead (Fig. 3). Evaluation at 18-month follow-up in an outpatient clinic demonstrated that the patient was in good condition and both pacemaker leads had stable electrical parameters. In the presented case we could have implanted both leads via PLSVC. However, implantation of a stiff ICD lead through the PLSVC with a typical 'figure of alpha $(\alpha)^{\prime}$ c configuration in the right atrium can result in deterioration of tricuspid valve function and predispose to lead failure in the long-term. The alternative approach would be implantation of the whole ICD system on the right side of the chest. In such cases, however, a second surgical intervention and dual-coil ICD lead would be necessary. The use of IV for implantation of an ICD lead allowed us to avoid problems related to the loop in the right atrium and place the ICD generator on the left side of the chest connected to a single-coil lead. Implantation of a dual-chamber ICD system in patients with rare venous anatomical anomalies is technically difficult, if not impossible. In cases of visualisation of left IV on intraoperative venography, it may be used for the placement of a lead. Interestingly, in patients with co-existing PLSVC IV usually has a small calibre, and it is challenging to place more than one lead through its lumen. The presented case draws attention to the difficulties that are encountered during implantation of an ICD in patients with PLSVC. PLSVC is a rare congenital venous anomaly that impedes placement of various cardiac implantable electronic devices. It is reported to occur in $0.3-2.0 \%$ of the general population. The routine use of pre-operative venography enables the operator to choose the optimal procedural strategy in patients with asymptomatic congenital venous anomaly.

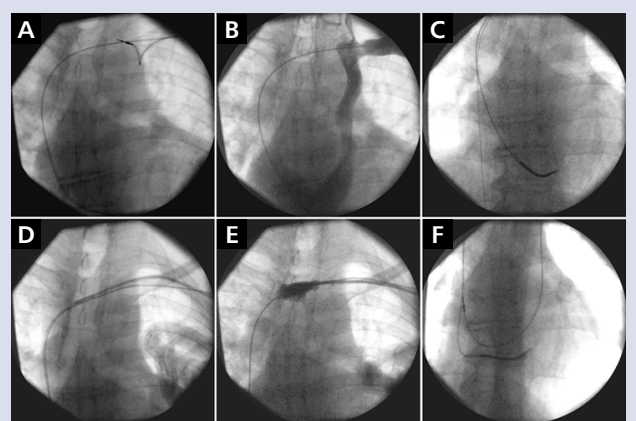

Figure 1. A-F. Subsequent stages of dual-chamber implantable cardioverter-defibrillator implantation

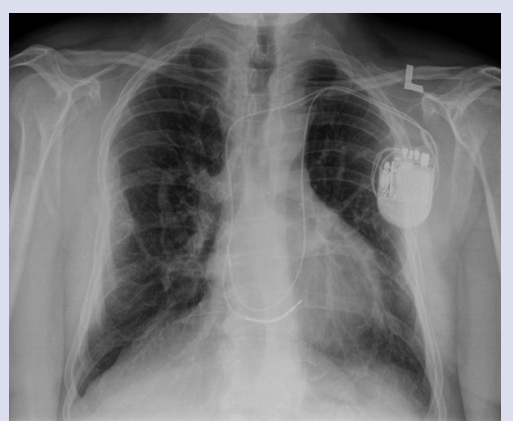

Figure 2. Chest X-ray after implantation of dual-chamber implantable cardioverter-defibrillator

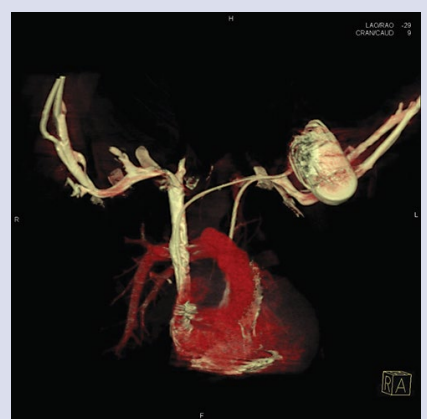

Figure 3. Angio-computed tomography revealing lack of contrast flow through IV

Address for correspondence:

Andrzej Ząbek, MD, PhD, MSc, Department of Electrocardiology, The John Paul II Hospital in Krakow, ul. Prądnicka 80, 31-202 Kraków, Poland, e-mail: andrzej__z@poczta.onet.pl

Conflict of interest: none declared

Kardiologia Polska Copyright (c) Polskie Towarzystwo Kardiologiczne 2017 